\title{
The Impact of Private Interest Contributions on Energy Policy Making.
}

\author{
Steffen Jenner ${ }^{a}$, Lotte Ovaere ${ }^{b}$, Stephan Schindele ${ }^{c}$ \\ ${ }^{a}$ University of Tuebingen, Melanchthonstrasse 36, 72074 Tuebingen, Germany, \\ steffen.jenner@uni-tubingen.de, +49-7071-29-72927. \\ ${ }^{b}$ Katholieke Universiteit Leuven, Oude Markt 13, Bus 50053000 Leuven, Belgium, \\ lotte.ovaere@econ.kuleuven.be, +32-163-26637. \\ ${ }^{c}$ Fraunhofer Institute for Solar Energy Systems, Heidenhofstr. 2, 79110 Freiburg, Germany, \\ stephan.schindele@ise.fraunhofer.de, +49-761-458-85961.
}

\begin{abstract}
In the last two decades, many U.S. states introduced support policies to promote electricity generation from renewable energy sources. Renewable portfolio standards are their most popular policy choices to date. This paper tackles the question why some state legislators were front-running the trend of RPS implementation while others adopted policies just recently, and again others have not incentivized investment so far. In short, what drives states to support renewable energy?

We base our empirical analysis on theoretical reasoning. First, we present an application of the common agency model developed by Dixit et al. (1997) to better understand the impact of special industrial interests on policy decision-making. Second, we compile data on financial contributions of conventional energy interests (CEI) and renewable energy interests (REI) to state-level policymakers between 1998 and 2006. Third, in a series of panel, hazard and tobit regressions, we test the impact of these financial contributions on (i) the probability of a state to adopt a RPS policy and (ii) on the stringency of the RPS. We also control for state effects, time trends, and a set of socio-economic and political covariates.

Combining our empirical framework with the theoretical model produces key insights into U.S. state level energy policy making. First, CEI have donated more to state-level legislators affiliated with the Republican Party than to Democrats while contributions from REI went largely to the latter. Second, we reveal statistically significant links between the likelihood of RPS adoption and private interest contributions. Financial contributions from CEI have a negative impact on the likelihood of RPS adoption while REI contributions have a positive impact. Third, the estimates show a similar - albeit less significant - pattern on RPS stringency.
\end{abstract}

Keywords: Renewable Portfolio Standards, Public Choice Model, Hazard Regression Model, Tobit Regression Model.

JEL Classification: $C 41, H 23, H 71, Q 48$

Acknowledgements: The authors would like to thank Stephen Ansolabehere, Robert Brückmann, William Clark, Richard Freeman, Jens Hainmueller, Aoife Haney, Stef Proost, Richard Schmalensee, Eva Schmid, Josef Schmid, James Snyder, Dustin Tingley, Eicke Weber, and Daniel Ziblatt for their valuable comments that substantially improved this article. Support from the the KUL Energy Institute, the Friedrich-Ebert-Foundation and the Fraunhofer ISE is gratefully acknowledged. The views expressed have not been endorsed by the sponsoring agencies. Any remaining errors, omissions, or inconsistencies are the authors' alone. 


\section{Introduction}

In the last two decades, many U.S. states introduced support policies to promote electricity generation from renewable energy sources (RES-E). Renewable portfolio standards (RPS) are their most popular policy choices.

A RPS policy requires utilities to produce a certain fraction, or "quota" of their total electricity supply from renewable energy sources. Most legislation allows trading of renewable energy certificates (REC) in-state or in larger REC-markets. Thus, utilities can either buy RES-E directly from RES-E producers or they compensate noncompliance of the quota by trading REC. Most RPS policies include penalties to incentivize compliance.

To date, 29 states employ a mandatory RPS while 7 other states have a voluntary RPS in place. Table 1 shows the timeline of RPS implementation from 1996 to 2010. In 1996 only three states had implemented an RPS. In 2010 already 36 states supported RES-E generation by means of RPS policies.

Table 1 - Years of RPS policy enactment at the U.S. state level from 1996 to 2010

\begin{tabular}{|c|c|c|c|c|c|c|c|c|c|c|c|c|c|c|}
\hline & & & & & & & & $\begin{array}{l}\mathrm{CO} \\
\mathrm{HI}\end{array}$ & & & $\begin{array}{l}\text { IL } \\
\text { NC }\end{array}$ & $\begin{array}{l}\text { MI } \\
\text { MO }\end{array}$ & & \\
\hline $\mathrm{AZ}$ & MA & $\mathrm{CT}$ & & & & & & $\mathrm{MD}$ & $\mathrm{DE}$ & & $\mathrm{NH}$ & $\mathrm{OH}$ & & \\
\hline IA & $\mathrm{ME}$ & PA & NJ & & & CA & & NY & MT & $N D$ & OR & $S D$ & $\mathrm{KS}$ & \\
\hline $\mathrm{MN}$ & $\mathrm{NV}$ & WI & $\mathrm{TX}$ & & & NM & & RI & $V T$ & WA & $V A$ & $\boldsymbol{U} \boldsymbol{T}$ & $\boldsymbol{W V}$ & $O K$ \\
\hline 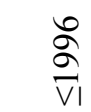 & $\hat{\alpha}$ & $\stackrel{\infty}{\curvearrowright}$ & ळे & ஓ્ఠ & 홍 & ণิ & ڤ్రి & ষ্ণ & ஜి & ஓ̊ํㅇ & 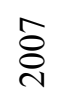 & $\stackrel{\infty}{\circ}$ & ஓे & $\stackrel{\circ}{\stackrel{2}{\circ}}$ \\
\hline
\end{tabular}

Mandatory RPS (standard); voluntary RPS (italic), Source: DSIRE (2012).

This paper tackles the question why some state legislators were front-running the trend while others adopted policies just recently, and again others have not incentivized investment so far. In short, what drives states to support renewable energy?

Previous studies shed light on an array of driving factors: geography (solar radiation, available land area, wind speed, conventional energy reserves etc.), economics (unemployment rate, disposable personal income, electricity price etc.), environmental protection (non-attainment area, critical air pollutants, greenhouse gas (GHG) emissions etc.), population (population size, educational level, citizens' environmental preferences etc.), politics (party ideology, governorship, state-to-statelearning etc.) and private interest (renewable energy interest groups, conventional energy interest groups, environmentalist groups, farmer lobbies etc.). Schmalensee (2011) nicely summarizes the political reasons to support renewables as energy security, green growth, and climate change.

We would like to amend the discourse by introducing a theory-based explanation and a rigorous econometric quantification of the impact of special industrial interest on state level energy policy-making. Thus, this paper contributes to the discourse in three ways.

First, we introduce a Public Choice model that elaborates the impact of private industrial interests on the willingness of policymakers to adopt RPS schemes. We call upon the common agency model developed by Dixit et al. (1997). We apply their model to the electricity market, and study the impact of special interest contributions on the probability that a politician will adopt support for RES-E. 
Second, we quantify the campaign contributions from renewable and conventional energy industries that were donated to state level policymakers. Previous studies have used binary codes for the pure existence of lobby groups only. We are thus able to capture more of the heterogeneity among private interests that would otherwise be lost in a binary code, e.g. the financial fire-power they bring to bear in the struggle for the politicians' attention.

Third, we regress this more nuanced covariate on the likelihood of policyadoption. We employ time-series cross sectional (TSCS), proportional hazard, and tobit models in combination with different sections of our panel data. The hazard model regresses the contribution variables on a binary variable that equals $1 / 0$ if a policy is/is not in place. Since the hazard model drops the state-years after a RPS has been adopted, the hazard model is best equipped to answer the first question: why do states adopt a RPS? The tobit regression regresses the covariate on the incremental share indicator (ISI) from Yin and Powers (2010) that quantifies the stringency of RPS policies. These censored regressions help to reveal the link between our covariate and the stringency of RPS policies, i.e. they focus on the state-years after a RPS has been enrolled. By means of the TSCS regressions, we show that un-censored models that run on the entire dataset and presumably skewed variables do not accurately capture the effect of financial contributions on RPS adoption and stringency.

The remainder of this article is structured as follows. Section 2 reviews the literature. Section 3 presents our application of the Dixit et al. (1997) agency model. Section 4 develops the covariate and provides the empirical framework. Section 5 presents and discusses the results. Section 6 concludes.

\section{Literature Review}

For our theoretical model we draw upon literature that studies why certain (inefficient) economic policies are selected as a result of the political process of lobbying (see Persson and Tabellini (2000) for a survey). The concept of interest groups as a possible reason for policy bias has been introduced by Olson (1965), and has proven to be a major contribution to the traditional public choice literature. The author states that groups that have overcome the collective action problem - and thus have organized themselves - have more impact on policy than non-organized groups. This idea has been formalized in a growing literature on lobbying. An extensive overview on lobbying literature is found in Rodrik (1995) and Austen-Smith (1997).

When several lobby groups, often with conflicting preferences, are affected by the action of a particular individual, the principal-agent interaction is formalized as a common agency model. In these models, special interest groups offer transferable utility (e.g. bribes, campaign contributions) to a government agent. In equilibrium, the agent efficiently aggregates the competing principals' influences, absent transaction costs. Common agency models have been widely used to model political distortions in domains such as public finance (Dixit et al. 1997) and environmental policy making (Aidt 1998). We apply the common agency model to the electricity market in presence of support for renewable energy.

Concerning the empirical part of our paper, there is a lively discourse of econometric studies that assess the motivations of renewable energy support policies. Knittel's (2006) applies a hazard model. He finds that residential wealth, a proxy for residential interest group activity correlates positively with the adoption of electricity 
market regulation. Lower levels of residential electricity penetration rates and lower electricity capacity also increase the likelihood of regulation. We learn from Knittel's (2006) proportional hazard model. However, we do not use electricity market regulation but the adoption and stringency of RPS schemes as dependent variables.

Huang et al. (2007) also run a logistic model on the U.S. states. Their results show that states with relatively high gross states products are more likely to implement a RPS. The probability of adoption also increases with population growth and the level of education of citizens. A RPS is less likely to be adopted if Republicans are holding a majority in state house and senate. High expenditure on conservation efforts of natural resources is also associated with lower RPS probabilities. We will use their dependent variable.

Chandler (2009) specializes in inter-state learning. His major contribution is to show that states are more likely to adopt RPS policies (and other renewable energy policies) if neighboring states have a RPS in place already. He conclusively argues that policies can diffuse across state borders even when the political environment is ideologically distanced. Chandler (2009) also finds that wealth, measured by personal disposable income, is another driver of RPS adoption. We also use this covariate to capture the diffusion impact.

Lyon and Yin (2010) build on the previous studies. They use a proportional hazard model like Knittel (2006) did and the dependent variable from Huang et al. (2007). In addition, they add variables that account for wind, biomass, and solar potentials. Lyon and Yin (2010) find that the unemployment rate and the percentage of natural gas generation have a negative impact on the odds of RPS adoption. In contrast, the existence of a staffed state chapter of the American Solar Energy Society (ASES), the percentage of Democrats in state legislation and a restructured electricity market elevate the likelihood of RPS adoption. Large wind and large solar potentials also make policymakers more willing to introduce a RPS. We follow Lyon and Yin (2010) by also calculating the odd ratios from the hazard model.

Lyon and Yin (2010) are the first study that links interest groups to the likelihood of RPS adoption. However, they quantify the impact of an interest group only by means of a binary code for the presence of a ASES state chapter. The real impact varies across states and time together with the financial resources of interest groups. Thus, our paper contributes to the discourse by introducing financial contribution covariates as more accurate and fine-grained measures of interest group influence. Furthermore, Lyon and Yin (2010) only capture the solar lobby, represented by the ASES. The solar lobby, however, is a weak proxy for renewable energy interest groups since RPS policies favor more price competitive RES-E sources such as wind and biomass. Therefore, the ASES may not even have an interest in the adoption of a RPS since solar photovoltaic and solar thermal technologies may not be used to meet the RPS quota. Finally, Lyon and Yin (2010) miss out on the opposing site of the game. Conventional energy producers are affected by the introduction of a RPS and thus lobby against it. Our study also incorporates contributions from conventional energy interests.

Delmas et al. (2011) is the most recent study on the U.S. sample. In a logistic model, they find that wind resources, solar resources, LCV Score, democrats in state legislation, income per capita, and the existence of state ASES chapters increase the probability of RPS adoption. Thus they also measure interest group influence by a dummy variable. Their regressions also present negative and significant impacts of biomass resources and the unemployment rate on the odds. 
Jenner et al. (2012) were the first to apply this question to RES-E policy making at the EU country level. They find that the existence of solar industry associations has a positive effect on the willingness of policymakers to adopt feed-in-tariffs (FiT). By means of technology-specific tailoring of tariff size and contract duration, FiT policies support technologies at different levels of market competitiveness. In other words, solar energy, being rather expensive to produce, is supported by many FiT policies (Groba et al. 2011). In turn, solar associations have an interest in the introduction of FiT policies. However, Jenner et al. (2012) capture the impact of interest groups by a dummy that neglects the heterogeneity between interest groups, states and years. Our covariate captures this kind of financial heterogeneity.

\section{Theoretical model}

In our theoretical model, we apply the common agency model (Dixit et al., 1997) to the electricity market. We use the model to study the impact of special interests on the level of support for renewable energy. Campaign contributions offered by the special interests create a political distortion, as the electorally motivated government agent exchanges these contributions for certain political favors. We proceed to show that campaign contributions are an important source of inefficiencies in support policies for renewable energy.

\subsection{The Economy}

We develop a stylized partial equilibrium model for a large, open economy, with two productive sectors: electricity $(x)$ and a numéraire $(y)$, and a distribution sector $(D)$. Electricity is produced in two subsectors, one using fossil fuels $(F)$ and the other using renewables $(R)$ as energy input (both traded at the world market). In order to support the renewables reaching grid parity, a renewable portfolio standard is introduced in the electricity sector. We define $\alpha(0 \leq \alpha \leq 1)$ as the annual RPS fraction (or quota). Thus, for each unit of electricity generated, $\alpha /(1-\alpha)$ certificates (REC) have to be provided. The REC price $\left(p_{c}\right)$ is determined on the REC market. It is partly determined by the target fraction $(\alpha) .{ }^{1}$ REC prices rise with increased RPS stringency if we assume that the current existing RES-E capacity does not meet $\alpha$. Per unit of output sold, the RESE producers receive the price of electricity on the market, plus an additional compensation for the certificates. We treat this compensation as a subsidy equivalent. ${ }^{2}$

Production in the numéraire sector is driven by a CRS technology that only uses labor $(l)$ as input factor. Labor mobility across sectors and profit maximization pin down the wage in the economy to $w=1$. Both the conventional and the renewable energy utility use three inputs: labor, industry specific capital in fixed supply $(k)$ and energy inputs $(f, r)$. Production is described by a neoclassical production function with constant returns to scale. Both electricity subsectors supply electricity in a competitive

\footnotetext{
${ }^{1}$ The scope of the scheme, the renewable technologies participating, and the price caps also affect the certificate price.

${ }^{2}$ Assuming the RPS is mandatory, the subsidy equals the additional cost of RES-E production relative to conventional electricity production.
} 
market. We have the following restricted profit function for the conventional producers: $\pi^{F}(Q, w, c)$, where $Q$ is the wholesale electricity price and $c$ the world market price for fossil fuels. The profit function is strictly convex and we have $\pi_{Q}^{F}>0, \pi_{c}^{F}<0$. The profit function for the renewables producers is $\pi^{R}\left(Q, w, g, \alpha, p_{c}\right)$, with $g$ the world market price for renewables. Profits are strictly convex, and we have $\pi_{Q}^{R}>0, \pi_{g}^{R}<0, \pi_{\alpha}^{R}>0$ and $\pi_{p_{c}}^{R}>0$. As levelized costs of RES-E generation exceed the levelized costs of electricity generation from conventional sources, we assume that $g>c .^{3}$ The distribution sector buys electricity from both producers, and sells it on to the end-user as a homogenous product, in a competitive market. The distributing companies are obliged to provide the fraction $\alpha$ of RES-E, which increases their costs. The distributor uses two input factors: labor and capital. The strictly convex profit function is: $\pi^{D}\left(P, Q, w, \alpha, p_{c}\right)$, with $\pi_{Q}^{D}<0, \pi_{P}^{D}>0, \pi_{\alpha}^{D}<0$ and $\pi_{p_{c}}^{R}<0$. The combination of the competitive setting in the distribution sector and the RPS obligation results in a wedge between the wholesale and the retail price: the consumer pays a mark-up for electricity compared to a situation in absence of a RPS. We have that $P=Q+\alpha p_{c}$. Consequently, demand for electricity is lower with an RPS obligation.

The economy has $\mathrm{N}$ consumers, who derive utility from consuming electricity $(x)$ and the numéraire $(y)$, and disutility from GHG and criteria air pollutants emitted by the conventional energy sector. ${ }^{4}$ The magnitude of these marginal emissions is fixed at a constant rate $(\varepsilon)$. Total emissions from the conventional energy sector are: $E=\varepsilon f$.

We define the harm caused by pollution as an increasing and convex function of total emissions: $H(E)$. We assume the utility of a consumer to be quasi-linear and additively separable, we have: $U_{h}=y+u(x)-H(E)$, with $u^{\prime}>0, u^{\prime \prime}<0$. Each consumer receives an income from two sources. For in-elastically supplying her endowment of labor, $l_{h}$, to the competitive labor market she gets a wage in return: $w l_{h}$. Profits of the electricity sector are in hands of the consumers, who each own a share, $\sigma_{h, i}$, of specific capital in sector $i(i=R, F, D) .{ }^{5}$ If we maximize utility subject to income, electricity price, and electricity production levels, we can derive the demand for electricity: $D(P)$, with $D^{\prime}(P)<0$. Demand for the numéraire is defined as follows: $D\left(p_{y}\right)=I-P D(P)$. If we assume that $D\left(p_{y}\right)>0$, the wage rate is well defined. We have the following indirect utility function for consumer $h$ :

$$
\begin{aligned}
V^{h}\left(P, Q, c, g, \alpha, p_{c}\right) & =l_{h}+\sigma_{h, F} \pi^{F}(Q, c)+\sigma_{h, R} \pi^{R}\left(Q, g, \alpha, p_{c}\right)+\sigma_{h, D} \pi^{D}\left(Q, P, \alpha, p_{c}\right) \\
& +u(D(P))-P D(P)-H(E)
\end{aligned}
$$

Assuming an additive utilitarian social welfare function, we have:

\footnotetext{
${ }^{3}$ This is mainly due to renewables' higher intermittency, higher specific upfront costs, lower overall load factor, additional transmissions costs, etc.

${ }^{4}$ Acknowledging the broad spectrum of additional positive and negative externalities, for simplicity reasons, we limit our model to emissions. Further externalities such as energy security, the impact on job creation and job destruction, volatility and size of electricity prices, impacts in trade, etc. would only multiply the magnitude of our coefficients. Thus, our findings give a valid insight into the direction of the impact. The actual size of the impact is probably even higher than our conservative estimates though.

${ }^{5}$ Human capital, e.g. entrepreneurial skills: only useful in a specific sector (cf. Aidt 1998).
} 


$$
\begin{aligned}
S W\left(P, Q, c, g, \alpha, p_{c}\right)= & L+\pi^{F}(Q, c)+\pi^{R}\left(Q, g, \alpha, p_{c}\right)+\pi^{D}\left(Q, P, \alpha, p_{c}\right) \\
& +N[u(D(P))-P D(P)]-N H(E)
\end{aligned}
$$

\subsection{The Political Process}

We consider a policymaker who must decide on whether or not to install a RPS in a certain year. The policymaker also sets the level of a RPS. The politician decides upon the optimal level of RES-E in the state economy in a given year, $\alpha^{*}$. If the existing level of RES-E capacity $(\beta)$ is smaller than $\alpha^{*}$ the politician will adopt a RPS. ${ }^{6}$ If $\alpha^{*}<\beta$ the politician will presumably not install a RPS. We model the decision making process on the optimal level of $\alpha$ as a common agency problem as did Dixit et al. (1997). The policymaker cares about social welfare, and collects private financial contributions during campaigning for office and the time being in office. These contributions will be used later on in an election, which is not modeled (cf. Aidt, 1998). The private industrial interests possibly affected by a RPS are willing to offer these contributions to influence the choice of the policymaker. ${ }^{7}$

We consider functionally specialized interest groups, in the sense that they only care for one specific objective (cf. Aidt 1998). In our model, we allow for conventional energy interests (CEI) and renewable energy interests (REI). That means contributions from CEI (REI) represent a signal to the policymaker in support (opposition) of the adoption of a RPS if the state has not previously adopted a RPS. If a RPS is enacted already, contributions from CEI (REI) represent a signal to the policymaker in support (opposition) of increased stringency of the RPS.

We study the interaction between these private industrial interests and the politician in a policy game that has two stages. In the first stage, each interest group non-cooperatively and simultaneously presents a binding contribution schedule. In the second stage, the politician chooses the level of RPS $(\alpha)$ so as to maximize a weighted sum of social welfare and the preferences of the private industrial interests that are represented by the contributions. This is because he wants to be re-elected, and the probability of re-election partly depends on aggregate campaign contributions and on social welfare. In other words, the policymaker is sensitive not only to the social welfare but also to financial contributions. Thus, the overall welfare maximization yields:

$$
W_{P}(\alpha)=\lambda S W(\alpha)+(1-\lambda) \sum_{l} \gamma_{l} C_{l}(\alpha)
$$

where $C_{l}$ represents the contributions from the special interests $(l=C E I, R E I)$. The weight $\lambda(0 \leq \lambda \leq 1)$ represents the policymaker's benevolence towards the social welfare, the adverse $(1-\lambda)$ thus represents the benevolence towards the private

\footnotetext{
${ }^{6}$ This level is given in our model, and depends on, amongst others, the level of natural resources in the economy, other support systems like tax cuts etc. $\beta>0$ indicates that renewable electricity production is viable, even without the support of a RPS.

${ }^{7}$ The private industrial interests are not necessarily collectively (e.g. industrial association, pressure group) organized, a 'group' can also consist of one individual. The connecting element lies in the shared target of supporting or opposing the adoption of a RPS.
} 
industrial interests. The weights $\gamma_{l}$ represent the relative influence of CEI vs. REI on the government. We assume $\gamma_{l} \in\{0,1\}$ and $\sum_{l} \gamma_{l} \leq 1$. This parameter represents the result of the competition (not modeled) between the two groups, as well as the preference of the policymaker towards either one of the interest group types. The weights are exogenous in our model and will remain exogenous in the empirical analysis as well. We focus on the outcome instead.

The equilibrium of the game is a subgame-perfect Nash equilibrium in the contribution schedules and the chosen RPS policy. The derivation of the equilibrium in differentiable strategies follows Grossman and Helpman (1994) and Dixit (1996) and is left out. In addition, for simplicity, we only consider those equilibriums in truthful contribution schedules (cf. Aidt, 1998 and Persson and Tabellini, 2000). ${ }^{8}$ As a result, we can write the objective function of the policymaker as:

$$
W_{P}(\alpha)=\lambda S W(\alpha)+(1-\lambda) \sum_{l} \gamma_{l} W_{l}(\alpha)
$$

where $W_{l}$ is the welfare of $l: C E I, R E I$. The welfare function of the REI group (and thus its contribution schedule) is the sum of the objective functions of consumers that favor renewable energy, either because they own shares in the sector, or because they are part of an environmentalist group. The function is defined as:

$$
W_{R}(\alpha)=\sum_{h \in R E I} \sigma_{h, R} \pi^{R}-S_{R} N H(E)
$$

where $s_{R}$ is the share of environmentalists in the population. This welfare function represents the preferences of the median consumer with renewable energy interests. As we do not model the organization process of special interests, we can consider this welfare function as if it were that of one lobby group. The CEI group is interested in maximizing the profit of the conventional energy sector. Their welfare function is the sum of the objective functions of all individuals that actively favor conventional energy because they own shares in the sector. It is defined as:

$$
W_{F}(\alpha)=\sum_{h \in C E I} \sigma_{h, F} \pi^{F}
$$

This welfare function represents the preferences of the median consumer with conventional energy interests. As we do not model the organization process of special interests, we can consider this welfare function as if it were that of one lobby group.

If the policymaker is entirely benevolent to social welfare, the optimal level of $\alpha$ maximizes social welfare, i.e. $\alpha$ is at a level that balances social and private benefits and costs of RPS. The benevolent politician maximizes social welfare as defined in the welfare function. Solving the first order condition leads to an implicit solution for the politically optimal level of $\alpha$, which we label as $\alpha^{*}$. The details of the calculations are provided in the Appendix. The policymaker compares this level of $\alpha^{*}$ to the existing level of RES-E capacity $(\beta)$, and will decide to support RES-E through a RPS if

\footnotetext{
${ }^{8}$ A globally truthful contribution schedule of an interest group everywhere reflects the true preferences of an interest group (cf. Aidt 1998). This means that the contributions schedule equals the welfare of the interest group, minus a constant that distributes the rent between the politician and the interest group (we set this constant equal to zero - all rent goes to politician).
} 
$\alpha^{*}>\beta$. The objective function of the policymaker who is not only sensitive to social welfare, but also to contributions is:

$$
\max _{\alpha} W_{P}(\alpha)=\lambda S W(\alpha)+(1-\lambda)\left[\gamma_{R} W_{R}(\alpha)+\gamma_{F} W_{F}(\alpha)\right]
$$

Straightforward, the optimal level of $\alpha$ now also depends on the relative size of the CEI and REI contributions, on the benevolence balance of the policymaker and on the relative assertiveness of CEI and REI on the decision making process. To study the effect of contributions from REI, we consider the following maximization issue for the policymaker:

$$
\max _{\alpha} W_{P}(\alpha)=\lambda S W(\alpha)+(1-\lambda)\left[\sum_{h \in R E I} \sigma_{h, R} \pi^{R}-s_{R} N H(E)\right]
$$

The policymaker will no longer opt for the socially efficient level $\alpha^{*}$. We find that the optimal support level for the RPS policy in this case, which we define as $\alpha^{R}$, exceeds $\alpha^{*}$ (see Appendix). The politician compares the level of $\alpha$ again to the existing capacity $\beta$ to decide whether or not to support RES-E. As $\alpha^{R}>\alpha^{*}$, the chance of the policymaker supporting RES-E increases in the presence of renewable energy special interests. The effect of contributions from CEI is determined by looking at the following objective function for the policymaker:

$$
\max _{\alpha} W_{P}(\alpha)=\lambda S W(\alpha)+(1-\lambda)\left[\sum_{h \in C E I} \sigma_{h, F} \pi^{F}\right]
$$

Again, the socially efficient level $\alpha^{*}$ will no longer be chosen. In this scenario, the politician opts for a level $\alpha^{F}$ that is lower than $\alpha^{*}$ (see Appendix). The politician compares the level of $\alpha$ again to the existing capacity $\beta$ to decide whether or not to support RES-E. As $\alpha^{F}<\alpha^{*}$, the chance of the policymaker supporting RES-E decreases in the presence of conventional special interests.

Applying the well-established Dixit et al. (1997) common agency model to the electricity market allows us to model how campaign contributions are an important source of inefficiencies in the support for renewable energy. The next section will test the core hypothesis that policymakers are sensitive to CEI and REI contributions. We assume that CEI contributions have a negative effect on the probability of RPS adoption and on the stringency of the RPS while REI contributions come with positive impacts.

\section{Empirical Framework and Data}

From Section 3 we know that the policymaker is sensitive to the maximization of social welfare and possibly also to private interest contributions. Our empirical analysis intends to verify or falsify the hypothesis that policymakers in the real world actually respond to private interests. We measure the impact of private interest with a covariate that captures financial contributions from CEI and REI respectively.

If there is a significant positive or negative link between our covariates for CEI or REI and the dependent variable, the hypothesis is verified for our sample. If the regressions reveal a significant neutral link, the hypothesis is falsified. If there is no significant link, we can neither verify nor falsify the hypothesis. 


\subsection{Dependent Variable}

In the subsequent empirical analysis, we will work with two different dependent variables. RPS Binary is a binary variable that indicates whether a RPS is enacted (1) or not (0). ISI is the incremental share indicator (ISI) from Yin and Powers (2010). The ISI represents "the mandated increase in renewable generation in terms of the percentage of all generation" (Yin and Powers, 2010: 1142). Thus it is a metric for policy stringency. The $I S I$ is constructed as

$$
I S I_{s t}=\frac{\eta_{i t}^{R E S} * \kappa_{i t}^{R E S} * q_{i t}^{\text {total }}-Q_{i T}^{R E S}}{q_{i t}^{\text {total }}}
$$

with $\eta_{i t}^{R E S}$ representing the yearly fraction as a percentage of RES-E to total electricity generation; $\kappa_{i t}^{R E S}$ representing the percentage of RES-E generation capacity that is legally eligible to meet $\eta_{i t}^{R E S} ; q_{i t}^{\text {total }}$ indicating the annual total electricity generation; and $Q_{i T}^{R E S}$ indicating the absolute RES-E generation capacity from previous years that is eligible to meet $\eta_{i t}^{R E S}$.

Data to construct RPS Binary has been provided by DSIRE (2012). Data for the ISI has been compiled from the EIA Electric Power Annual (2011). We use RPS Binary in the proportional hazard model. We use ISI in the tobit model. We first test both dependent variables in the fixed effects panel regression.

\subsection{Independent Variable}

Previous studies have mostly relied on binary codes that equal $1 / 0$ if an interest group does/ does not exist in the particular state $i$ in the given year $t$ (Delmas et al., 2011; Jenner et al., 2012; Lyon and Yin, 2010). We argue that this approach neglects the important heterogeneity between different interests that results from differences in the magnitude of their contributions. In other words, "money matters". The more financial "fire power" an industrial interest can spend, the better its chances to have an impact on the decision-making process.

We measure the amount of annual contributions that have been made to politicians at the U.S. state level between 1998 and 2010. Data on the individual contributions has kindly been provided by the National Institute on Money in State Politics, a non-partisan, non-profit organization (visit their outstanding webpage at FollowTheMoney.org). Their dataset contains contributions to U.S. state level policymakers from 1989 to 2011 . The data is comprehensive for all 50 U.S. states in 1998 and following.

From the total amount of individual contributions we filtered 473,747 contributions that came from conventional and renewable energy industries as well as pressure groups that are closely related to energy and/ or environmental issues. These interests would be affected directly by the introduction of a RPS. We distinguish between branches we assume to favor the introduction of a RPS, e.g. alternative energy producers and environmental protection groups; and groups we expect to favor to not have a RPS adopted, e.g. oil, natural gas and coal related industries and pro-resource development groups.

We assume contributions from conventional energy interests (we referred to them in Section 3 as "CEI") to have a negative impact on the probability of a policymakers to adopt a RPS while the aggregated contributions from the cluster of 
renewable energy interest ("REI") have a positive influence on the odds of adoption. Furthermore, we assume that CEI (REI) contributions have a positive (negative) effect on policy stringency. Figure 1 presents the development of CEI and REI contributions (in absolute terms) as an aggregate of all U.S. state level contributions from 1998 to 2010 (NMISP 2011).

Figure 1 - CEI and REI Contributions at the U.S. state level from 1998 to 2010

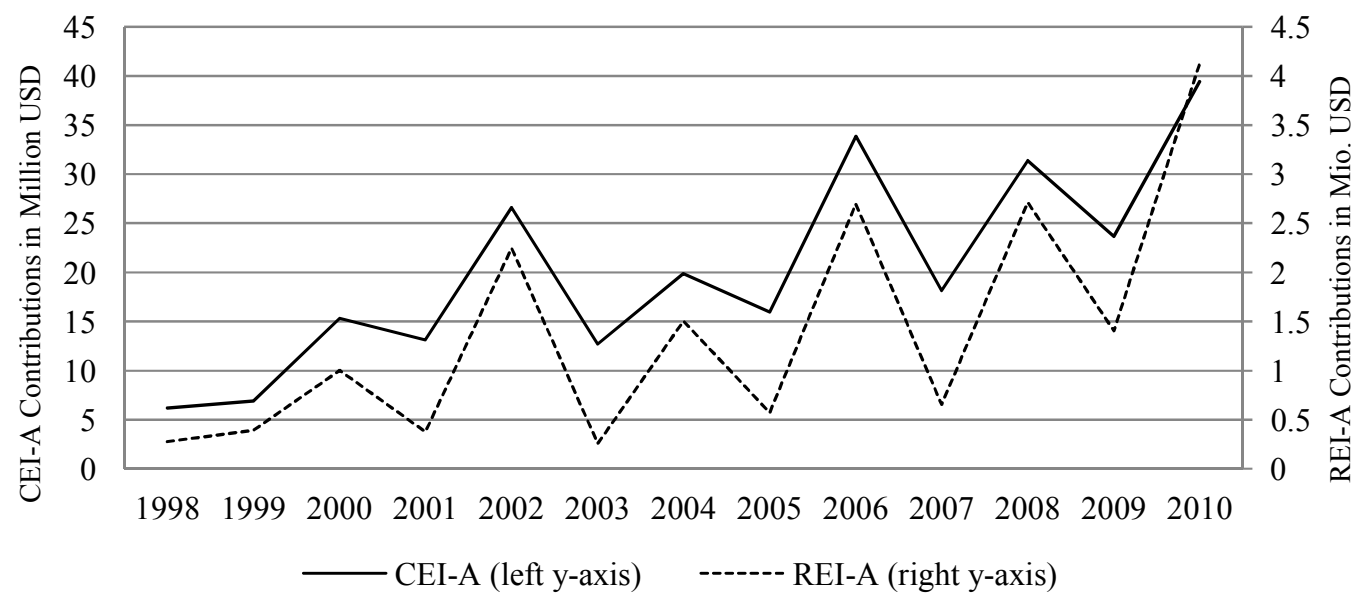

Figure 1 shows that both REI and CEI contributions fluctuate and increase over time. The fluctuations can be explained by frequency of state level elections. Thus, Figure 2 presents the years with gubernatorial elections (NCSL2011) and the total amount of contributions (NMISP 2011).

Figure 2 - Total Contributions and Elections at the U.S. state level from 1998 to 2010

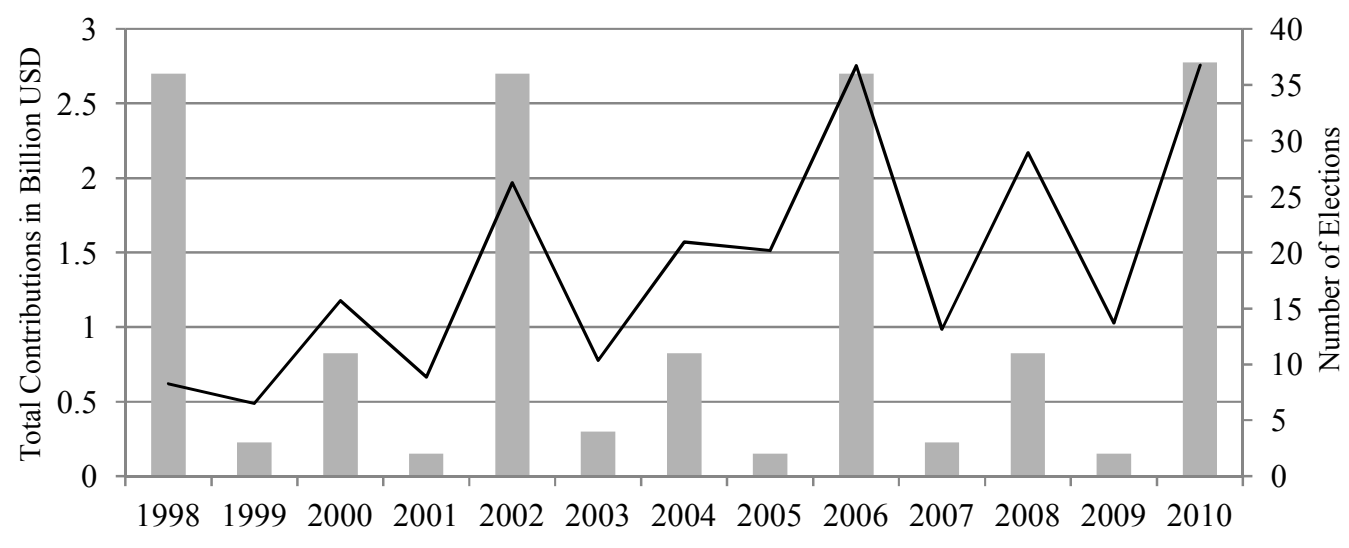

Number of State Elections (right y-axis) — Total Contributions (left y-axis)

Since elections appear to affect both total and energy sector contributions, building the ratios for CEI and REI to total contributions is an adequate way to accurately capture the impact of contributions. Ratios also help to control for the inflation trend that affects both energy sector contributions and total contributions.

Thus far, we described cross-state aggregates. However, there is quite some heterogeneity between states in the magnitude of both CEI and REI contributions. Figure 3 shows the distribution of CEI contributions between 1998 and 2010 among the 50 U.S. states. Figure 4 shows the distribution of REI contributions. 
Figure 3 - Geographical Distribution of CEI Contributions at the U.S. state level

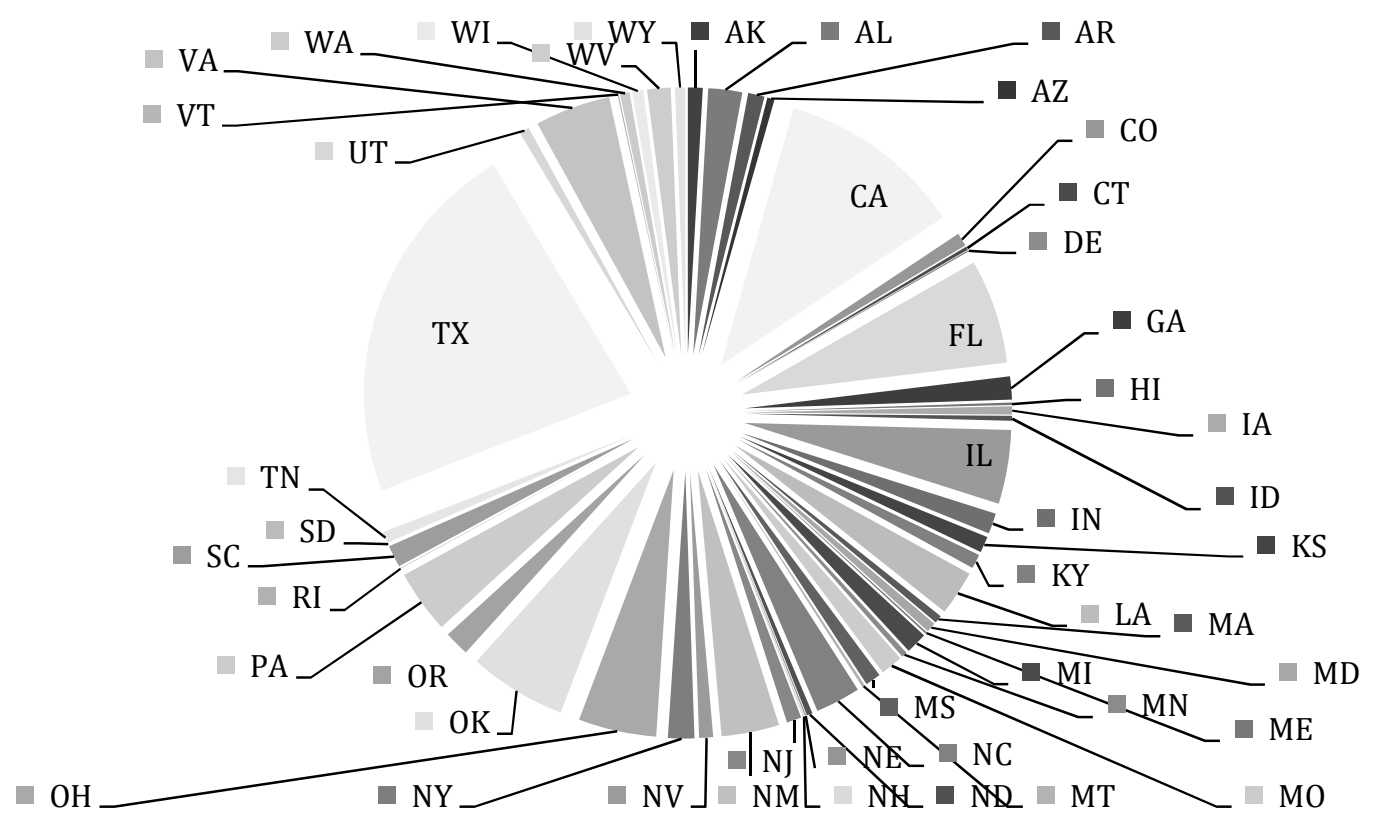

Figure 4 - Geographical Distribution of REI Contributions at the U.S. state level

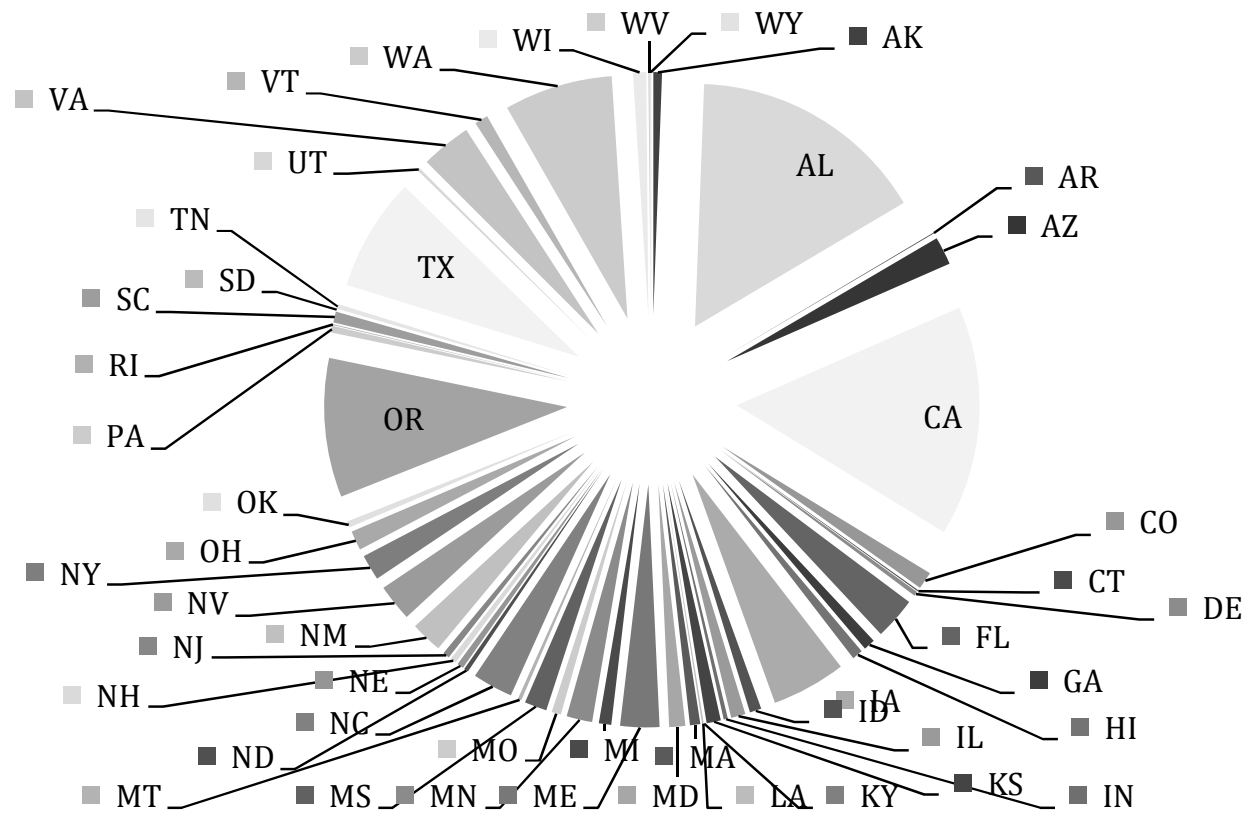

For our regressions, we use three kinds of covariates: Absolute contributions $C E I-A$ and $R E I-A$, the ratio of these contributions to the total contributions $C E I-R$ and $R E I-R$, and interaction terms. We build interaction terms for the ratios and the party affiliation of the governor. In addition, we interact the ratios with a lobby regulation index to evaluate the effect of lobby regulation on the assertiveness of the contributions. According to the theoretical model and what we just discussed along with Figures 1 and 2 , we argue that ratios are the best metric to capture the influence of contributions on the policymaker because ratios represent the relative importance of one private interest over others. 


\subsection{Controls}

Multiple aspects can determine the enactment and stringency of a policy. Our major interest lies in finding out to what extent private interest contributions drive these decisions. However, other variables also factor in the ultimate decision about enactment and stringency. In order to capture these influences, we control for a series of socioeconomic and political variables.

Republican Governor (GOV-R) and Republicans in State Legislature (LEG-R). Party theory argues that the ideological background has an impact on policymakers' decisions. The adoption of a renewable energy support scheme such as the RPS is a major decision in favor of state intervention into the electricity market. Following Lyon and Yin (2010) and Huang et al. (2007), we assume that Republican governors and Republicans in state legislature are more reluctant to introduce RPS schemes. The mean Voting Score published by the League of Conservation Voters (LCV) also shows that Democrats vote roughly 10 times more often in favor of environmental and climate policies than Republicans at the state level. $G O V-R$ is a binary code that equals " 1 " if the governor is affiliated with the Republican Party and " 0 " if the governor is a Democrat. $L E G-R$ represents the percentage of Republican members of the state houses and senates. The variables are correlated. Thus we use $G O V-R$ in our main model and $L E G-R$ in robustness checks. We will also use party affiliation of the governor as an interaction term with our $C E I-R$ and $R E I-R$ covariates.

Public Opinion $(P U B-R)$. Party affiliation is only one side of the story since there is considerable ideological heterogeneity within a party across states. For instance, Republican politicians in New England states tend to take more liberal or democratic positions than their colleagues in the Southern States. Similar to Lyon and Yin (2010), we capture the general political position of a state by the percentage of persons that describes themselves as "Republicans".

Neighboring states with RPS (N-RPS). The federalist political system of the U.S. fosters state-to-state learning. In the RPS case the diffusion of policies across neighboring states is of particular importance because regional renewable electricity certificate (REC) markets incentivize the adoption of RPS systems in recent years if neighboring states already institutionalized a REC market. Chandler (2009) found that the share of neighboring states that have a RPS in place positively affects the likelihood of adoption. We include Chandler's variable and assume its coefficient will also be positive.

State Income (INC) and Energy Sector Employment (E-EMPL). Public interest theory argues that policymakers are sensitive to the wealth of their constituents. Since the adoption of a RPS scheme brings energy capacities online that would not be price competitive in the absence of the policy, additional costs emerge. Utilities will forward these costs to the end-user. Policymakers in relatively poor states may be less willing to advocate the additional burden that comes from a RPS than policymakers in wealthier states. Knittel (2006) and Huang et al. (2007) found such a link. Therefore, INC represents the median income of a 4-person household. The share of mining and utility sector employment in total employment, E-EMPL, follows a similar rational. We expect policymaker in states with high mining and utility sector employment to be less motivated to adopt a RPS that could threaten these jobs.

Non-Attainment Area Index (NAA). Public health benefits from the replacement of conventional energy sources by renewable energy sources because their generation 
produces less toxic air pollutants and emissions. Lyon and Yin (2010) and Chandler (2009) found that policymakers in states where many people live in so-called nonattainment areas are more likely to support a RPS. Therefore, we include the EPA (2011) data for local air pollutants per 2000 population. The ratio represents the level of exposure to critical air pollutants. $N A A$ presumably increases the odds of RPS adoption.

$R E S-E$ Capacity (RES-CAP). Existing renewable energy capacities make it easier for policymakers to support RES-E generation. One rational is that these technologies have already proven their market competitiveness. Another rational is that RPS can protect existing RES-E to stay in the market even when unconventional energy sources such as shale gas enter the market. Following Lyon and Yin (2010) we include the percentage of non-hydro RES-E in total electricity capacity. The variable is used in models with RPS Binary as the dependent variable. We drop RES-CAP if ISI is the dependent variable because, by design, the former is endogenous to the latter.

Lobby Regulation Index (REG). The effectiveness of private interest groups to influence the decision making process is also affected by the receptiveness of the political system itself. Newmark (2005) constructed a lobby regulation index that captures the number of lobby regulations at state level. We took the 2003 score of this index which means the variable is time invariant. Controlling for it may result in lower coefficients for the other covariates because these kind of fixed effects take out parts of the distribution of the dependent variables. Thus we interact $R E G$ with the $C E I-R$ and $R E I-R$ covariates.

In a series of robustness checks we also tested a couple of additional control variables such as the percentage of GDP that is contributed by the energy and mining industries, greenhouse gas emissions per capita, population growth, solar irradiation and others. We do not include these controls because they intercorrelated with other variables and thus would have possibly biased the estimates.

\subsection{Data}

We compiled 1998-2010 panel data on RPS policies, the contributions, and most of the control variables for the U.S. 50 states sample. Contribution data has kindly been provided by the National Institute on Money in State Politics (NMISP), a non-partisan, non-profit organization. Other data has been compiled from the EIA (2011), EPA (2011), DSIRE (2012), BLS (2011), BEA (2011), and NCSL (2011). The public opinion dataset is private data from Harvard University. It ranges to 2006 only. Thus we limited the empirical framework to 2006. If comprehensive public opinion data is available in the future, we can easily extend the dataset by four years. In Table 2, the summary statistics of the dataset are presented. 
Table 2 - Summary Statistics

\begin{tabular}{llllllll}
\hline \hline & Obs. & Mean & Std. Dev. & Min & Max & Unit & Source \\
\hline RPS Binary & 650 & 0.15 & 0.36 & 0 & 1 & Binary & NMISP (2011) \\
ISI & 650 & 1.16 & 4.46 & 0 & 32.10 & $\%$ & NMISP (2011) \\
\hline REI-A & 650 & 28.05 & 79.89 & 0 & 839.60 & $\$ 1,000$ & NMISP (2011) \\
CEI-A & 650 & 404.95 & 917.91 & 0 & 11144.14 & $\$ 1,000$ & NMISP (2011) \\
REI-R & 650 & 0.02 & 0.07 & 0 & 1.55 & $\%$ & NMISP (2011) \\
CEI-R & 650 & 0.27 & 2.61 & 0 & 41.72 & $\%$ & NMISP (2011) \\
\hline GOV-R & 650 & 0.52 & 0.50 & 0 & 1 & Binary & NCSL (2011) \\
PUB-R & 450 & 38.48 & 8.57 & 0 & 73.68 & $\%$ & private \\
N-RPS & 650 & 25.09 & 28.39 & 0 & 100.00 & $\%$ & DSIRE (2012) \\
INC & 650 & 51.73 & 7.84 & 35.58 & 73.60 & $\$ 1,000$ & BEA (2011) \\
E-EMPL & 650 & 1.16 & 1.33 & 0 & 9.29 & $\%$ & BLS (2011) \\
NAA & 650 & 0.36 & 0.58 & 0 & 2.41 & $\%$ & EPA (2011) \\
RES-CAP & 650 & 4.12 & 4.94 & 0 & 27.59 & $\%$ & EIA (2011) \\
\hline LEG-R & 650 & 47.91 & 15.07 & 10 & 89.00 & $\%$ & NCSL (2011) \\
REG & 650 & 10.34 & 3.12 & 1 & 17.00 & Index & Newmark (2005) \\
\hline \hline
\end{tabular}

\subsection{TSCS Model}

We first run preliminary times series cross-sectional regressions. A Hausman test rejects the null hypothesis. Thus, we incorporate state and year fixed effects. State effects control for any time constant characteristics such as the institutional environment or the RES-E potential. Time effects control for federal economic and policy impacts that are invariant to states. The model specification is written as:

$$
\text { (I) } \quad D V_{i t}=\propto_{0}+\beta_{1} \boldsymbol{C E} \boldsymbol{I}_{i t}^{\boldsymbol{R}}+\beta_{2} \boldsymbol{R} \boldsymbol{E} \boldsymbol{I}_{i t}^{\boldsymbol{R}}+\beta_{x} Z_{i t}+\gamma_{1} \mu_{i}+\gamma_{2} \mu_{t}+\epsilon_{\mathrm{it}}
$$

where $Z_{i t}$ is a suite of our controls; $\mu_{i}, \mu_{t}$ represent the fixed effects; and $\epsilon_{i t}$ is an error term. $D V_{i t}$ takes the form of either RPS Binary or ISI. In some specifications, $C E I^{R}$ and $R E I^{R}$ are replaced with $C E I^{A}$ and $R E I^{A}$ or interaction terms.

We expect this linear model to actually be inappropriate for our first question regarding what drives states to adopt a RPS policy. First, our dependent variable RPS Binary is a binary code and not normally distributed. Second, we are actually only interested in the state-years prior to the enactment of a RPS since we want to estimate the factors that lead up to the decision. Thus, the estimates are biased by state-years after the policy has been enacted. It is also important to exclude state-years after policy adoption because RPS policies may have an effect on the contributions of interest groups, i.e. the independent variable may well be endogenous to the dependent variable after it turns "1".

\subsection{Hazard Model}

Hazard modeling (Kiefer 1988), which is commonly applied in labor market economics and public health studies, is a more appropriate technique to solve these kinds of problems. First, the dependent variable is defined as the conditional probability $P_{1}=P(t, X, Z)$ of a state to adopt regulation in a certain year, given the state did not adopt such regulation before: $P_{0}=1-P(t, X, Z)$ (Jenkins 1995). Second, the model drops the state-years in the first year after policy enactment. Thus, it is more robust against the endogeneity bias. By only using the state-years leading up to the decision, the 
proportional hazard model specifically addresses our first question of what drives states to adopt a RPS. The logistic model allows transferring the coefficients into odd ratios. Thus, the model estimates the relative effect of a mean unit change on the probability of a state adopting a RPS in year $t$ given that the state has not adopted a RPS before. The logit specification is written as follows:

$$
\operatorname{logit}\left\{\operatorname{Pr}\left(P_{1} / P_{0}\right)\right\}=\lambda_{0}(t)+\beta_{1} \boldsymbol{C E} \boldsymbol{I}_{i t}^{R}+\beta_{2} \boldsymbol{R} \boldsymbol{E} \boldsymbol{I}_{i t}^{\boldsymbol{R}}+\beta^{\prime} Z_{i t}+\varsigma_{i}+\epsilon_{i t}
$$

where $\lambda_{0}(t)$ is the baseline hazard of RPS adoption only determined by time; $C E I$ and $R E I$ are the contribution ratios; $Z_{i t}$ is a suite of political, energy, environmental, and socio-economic controls expected to have an impact on RPS adoption; $\zeta_{i}$ is the statespecific random-intercept that covers the otherwise omitted time-constant state impacts that cause some states to generally be more likely to adopt RPS schemes than others; $\epsilon_{i t}$ is the error term.

A robustness option excludes the 5\% outliers at the left and right hand side of the distribution. We expect this model to generate more meaningful results than the TSCS model since it uses the probability of policy adoption as the dependent variable and excludes state-years after policy adoption.

Figure 5 presents the Kaplan-Meier hazard function. The exponential slope of the curve illustrates the increasing willingness of policymakers across states to adopt a RPS policy. In 2010, the curve ends at $72 \%$. The remaining $28 \%$ represent the 14 states that have not yet implemented a RPS (see Table 1).

Figure 5 - Kaplan-Meier Hazard Function

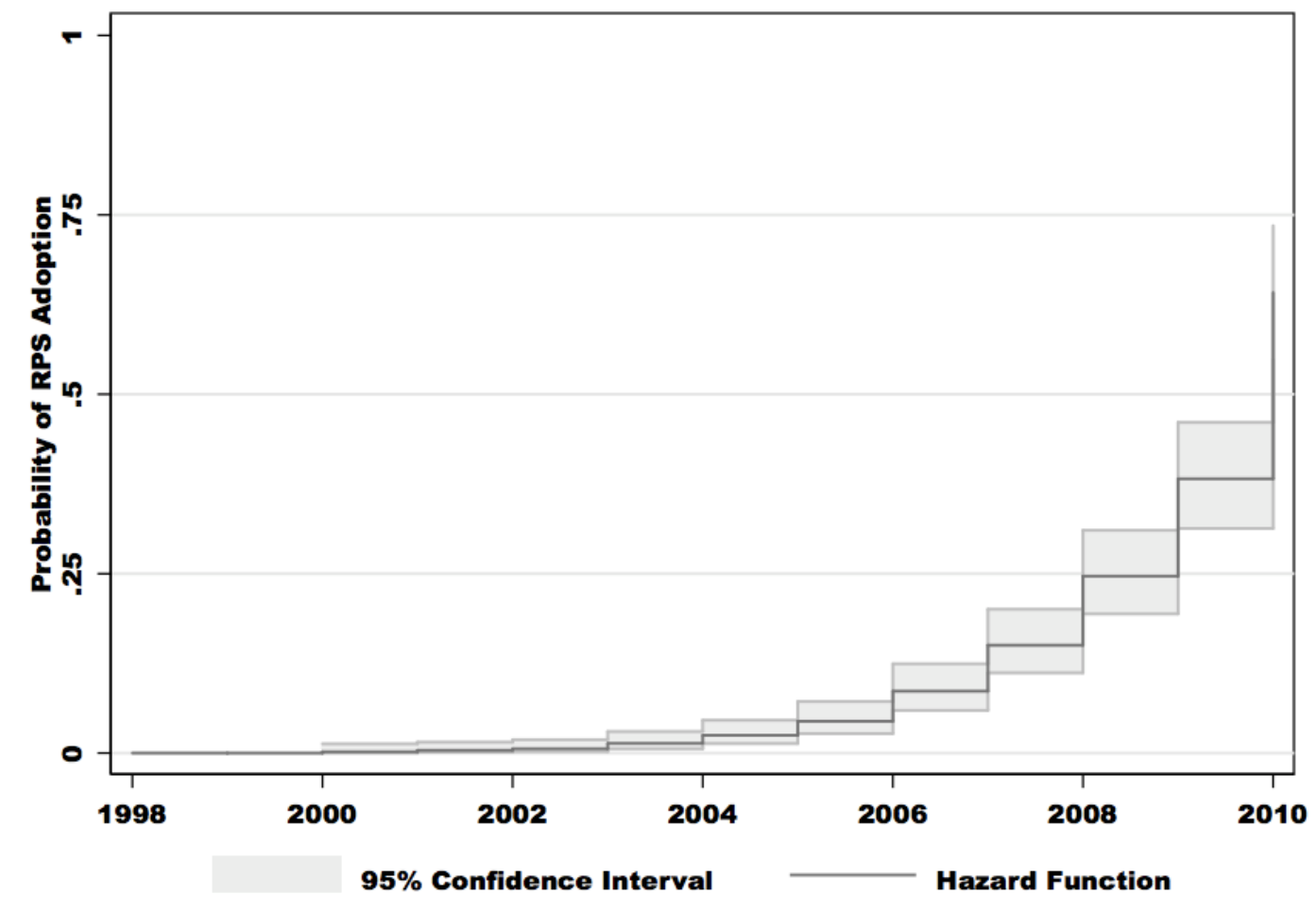




\subsection{Censored Model}

The hazard model investigates the link between our covariates and the likelihood of RPS adoption. As soon as an RPS is adopted, the hazard model drops the data points. In order to analyze the effect of our covariate on the policy stringency after the RPS has been enrolled; we apply a tobit regression model to the state-years that have been dropped by the hazard model. It allows using a stringent metric, the ISI (Yin and Powers 2009), as the dependent variable. The reason for applying a tobit model lies in the fact that the ISI has a lower threshold namely zero. That means that the distribution of the $I S I$ is limited to positive values down to the threshold of zero.

$$
I S I_{i t}=\lambda_{0}(t)+\beta_{1} \boldsymbol{C E} \boldsymbol{I}_{i t}^{R}+\beta_{2} \boldsymbol{R} \boldsymbol{E} \boldsymbol{I}_{i t}^{R}+\beta^{\prime} Z_{i t}+\varsigma_{i}+\epsilon_{i t}
$$

as specified for the logistic regression. The sample of the tobit regression comes with a lower limit of 0.001 for the ISI. The reason for this censoring is to only capture the observations that have a RPS in place already.

\section{Empirical Findings}

A glance at descriptive statistics provides insight into the distribution of the contributions. Figure 6 shows a simple two-party comparison of the 1998-2010 aggregate of CEI-A and REI-A contributions. CEI have donated two to three time more state-level legislators affiliated with the Republican Party than to Democrats. In contrast, REI contributions to Democrats are roughly three times higher than to Republicans. This pattern holds true in absolute and per seat terms. We will use interaction terms and control variables to capture this party-bias.

\section{Figure 6 - Absolute CEI and REI contributions to Republicans and Democrats}

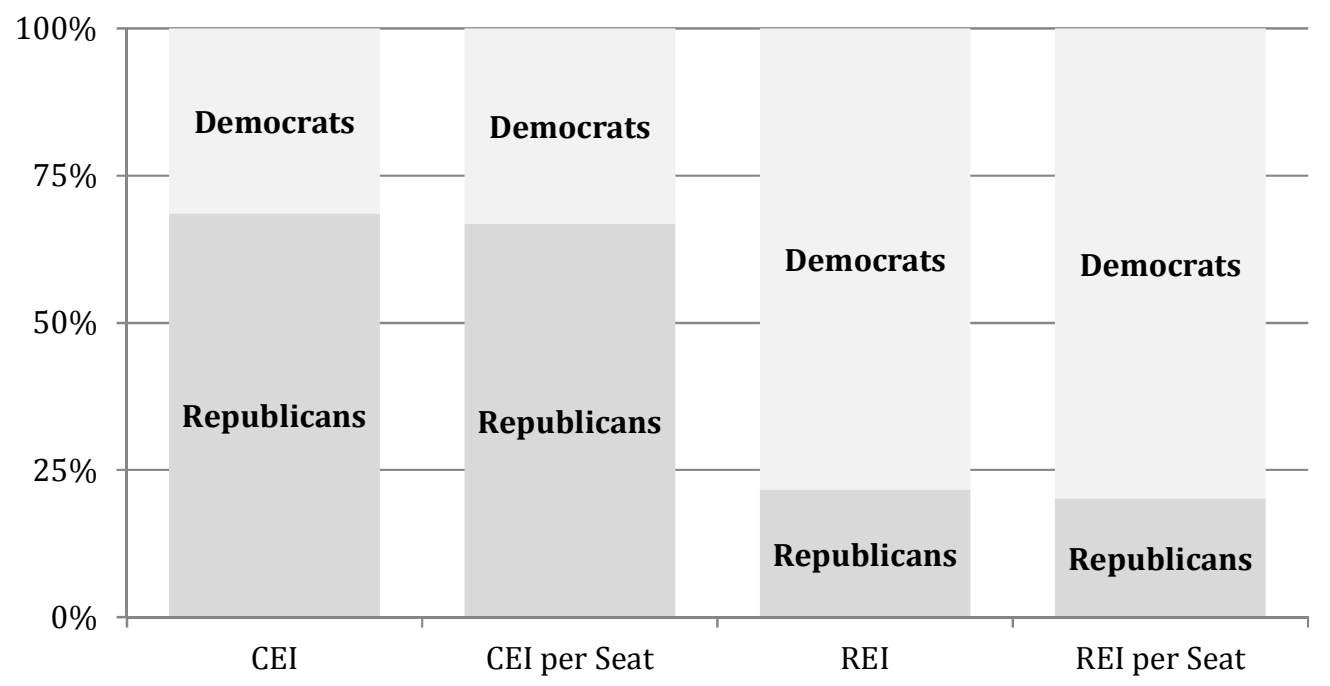

This imbalance verifies the hypothesis that private industrial contributions tend to be donated to likeminded politicians. The LCV score showed that Democrats are more likely to endorse renewable energy and climate policies than Republicans. REI contributors appear to know that and thus support Democrats to much larger extents than Republicans. The same logic holds true for CEI contributors and Republicans. Since Republicans are generally more likely to oppose environmental regulation, indicted by a low mean LCV score, CEI contributors support them in their stance 
against market intervention. Both findings come without much surprise. However, it shows that we need to control for party bias, and it verifies that party affiliation is a major driver of contributions in the first place.

We now go one step further and evaluate the impact of CEI and REI contributions on the willingness of policymakers to enact a RPS. Table 3 presents the results of our simple time series cross-sectional regression model (I). It does not reveal significant connections between CEI or REI contributions and the dependent variables RPS Binary or ISI.

Table 3 - Times Series Cross-Sectional Regression Results

\begin{tabular}{|c|c|c|c|c|c|c|c|c|}
\hline & \multicolumn{4}{|c|}{ RPS Binary } & \multicolumn{4}{|c|}{ ISI } \\
\hline & (X_B_1) & (X_B_2) & (X_B_3) & (X_B_4) & (X_I_1) & (X_I_2) & (X_I_3) & (X_I_4) \\
\hline REI-A & $\begin{array}{l}0.005 \\
(0.005)\end{array}$ & & & & $\begin{array}{l}0.089 \\
(0.093)\end{array}$ & & & \\
\hline CEI-A & $\begin{array}{l}-0.001 \\
(0.011)\end{array}$ & & & & $\begin{array}{l}-0.030 \\
(0.219)\end{array}$ & & & \\
\hline REI-R & & $\begin{array}{l}-0.003 \\
(0.002)\end{array}$ & & & & $\begin{array}{l}-0.004 \\
(0.025)\end{array}$ & & \\
\hline CEI-R & & $\begin{array}{l}-0.000 \\
(0.001)\end{array}$ & & & & $\begin{array}{l}-0.002 \\
(0.009)\end{array}$ & & \\
\hline REI-R x GOV-D & & & $\begin{array}{l}-0.001 \\
(0.003)\end{array}$ & & & & $\begin{array}{l}0.042 \\
(0.066)\end{array}$ & \\
\hline CEI-R x GOV-D & & & $\begin{array}{l}-0.000 \\
(0.000)\end{array}$ & & & & $\begin{array}{l}-0.003 \\
(0.007)\end{array}$ & \\
\hline REI-R x GOV-R & & & $\begin{array}{l}-0.004^{* *} \\
(0.002)\end{array}$ & & & & $\begin{array}{l}-0.004 \\
(0.037)\end{array}$ & \\
\hline CEI-R x GOV-R & & & $\begin{array}{l}-0.000 \\
(0.000)\end{array}$ & & & & $\begin{array}{l}0.000 \\
(0.004)\end{array}$ & \\
\hline REI-R x REG & & & & $\begin{array}{l}-0.002 \\
(0.002)\end{array}$ & & & & $\begin{array}{l}-0.002 \\
(0.018)\end{array}$ \\
\hline CEI-R x REG & & & & $\begin{array}{l}-0.000 \\
(0.001) \\
\end{array}$ & & & & $\begin{array}{l}-0.002 \\
(0.009)\end{array}$ \\
\hline GOV-R & $\begin{array}{l}-0.005 \\
(0.015)\end{array}$ & $\begin{array}{l}-0.006 \\
(0.016)\end{array}$ & $\begin{array}{l}-0.003 \\
(0.017)\end{array}$ & $\begin{array}{l}-0.007 \\
(0.016)\end{array}$ & $\begin{array}{l}0.304 \\
(0.285)\end{array}$ & $\begin{array}{l}0.298 \\
(0.310)\end{array}$ & $\begin{array}{l}0.314 \\
(0.318)\end{array}$ & $\begin{array}{l}0.286 \\
(0.312)\end{array}$ \\
\hline PUB-R & $\begin{array}{l}-0.073 \\
(0.067)\end{array}$ & $\begin{array}{l}-0.092 \\
(0.082)\end{array}$ & $\begin{array}{l}-0.092 \\
(0.082)\end{array}$ & $\begin{array}{l}-0.095 \\
(0.083)\end{array}$ & $\begin{array}{l}0.298 \\
(0.967)\end{array}$ & $\begin{array}{l}0.067 \\
(1.187)\end{array}$ & $\begin{array}{l}0.106 \\
(1.171)\end{array}$ & $\begin{array}{l}0.010 \\
(1.202)\end{array}$ \\
\hline N-RPS & $\begin{array}{l}0.037 \\
(0.036)\end{array}$ & $\begin{array}{l}0.033 \\
(0.037)\end{array}$ & $\begin{array}{l}0.034 \\
(0.037)\end{array}$ & $\begin{array}{l}0.032 \\
(0.037)\end{array}$ & $\begin{array}{l}0.937 \\
(0.742)\end{array}$ & $\begin{array}{l}0.999 \\
(0.800)\end{array}$ & $\begin{array}{l}1.004 \\
(0.803)\end{array}$ & $\begin{array}{l}0.981 \\
(0.800)\end{array}$ \\
\hline INC & $\begin{array}{l}0.107 \\
(0.153)\end{array}$ & $\begin{array}{l}0.096 \\
(0.153)\end{array}$ & $\begin{array}{l}0.100 \\
(0.156)\end{array}$ & $\begin{array}{l}0.089 \\
(0.151)\end{array}$ & $\begin{array}{l}1.431 \\
(3.489)\end{array}$ & $\begin{array}{l}1.888 \\
(3.457)\end{array}$ & $\begin{array}{l}1.959 \\
(3.458)\end{array}$ & $\begin{array}{l}1.749 \\
(3.437)\end{array}$ \\
\hline E-EMPL & $\begin{array}{l}-0.016 \\
(0.015)\end{array}$ & $\begin{array}{l}-0.016 \\
(0.016)\end{array}$ & $\begin{array}{l}-0.016 \\
(0.016)\end{array}$ & $\begin{array}{l}-0.016 \\
(0.016)\end{array}$ & $\begin{array}{l}0.075 \\
(0.381)\end{array}$ & $\begin{array}{l}0.062 \\
(0.427)\end{array}$ & $\begin{array}{l}0.068 \\
(0.423)\end{array}$ & $\begin{array}{l}0.057 \\
(0.432)\end{array}$ \\
\hline NAA & $\begin{array}{l}0.018 \\
(0.012)\end{array}$ & $\begin{array}{l}0.020^{*} \\
(0.012)\end{array}$ & $\begin{array}{l}0.019 \\
(0.012)\end{array}$ & $\begin{array}{l}0.021^{*} \\
(0.012)\end{array}$ & $\begin{array}{l}0.186 \\
(0.289)\end{array}$ & $\begin{array}{l}0.158 \\
(0.279)\end{array}$ & $\begin{array}{l}0.156 \\
(0.280)\end{array}$ & $\begin{array}{l}0.170 \\
(0.277)\end{array}$ \\
\hline RES-CAP & $\begin{array}{l}-0.007 \\
(0.010)\end{array}$ & $\begin{array}{l}-0.006 \\
(0.010)\end{array}$ & $\begin{array}{l}-0.006 \\
(0.010)\end{array}$ & $\begin{array}{l}-0.006 \\
(0.010)\end{array}$ & & & & \\
\hline constant & $\begin{array}{l}-0.003 \\
(0.015)\end{array}$ & $\begin{array}{l}-0.002 \\
(0.015)\end{array}$ & $\begin{array}{l}-0.002 \\
(0.015)\end{array}$ & $\begin{array}{l}-0.001 \\
(0.015)\end{array}$ & $\begin{array}{l}-0.221 \\
(0.341)\end{array}$ & $\begin{array}{l}-0.266 \\
(0.342)\end{array}$ & $\begin{array}{l}-0.276 \\
(0.339)\end{array}$ & $\begin{array}{l}-0.250 \\
(0.342)\end{array}$ \\
\hline Fixed Effects & Yes & Yes & Yes & Yes & Yes & Yes & Yes & Yes \\
\hline $\mathbf{N}$ & 450 & 450 & 450 & 450 & 450 & 450 & 450 & 450 \\
\hline R-Square & 0.1683 & 0.1696 & 0.1713 & 0.1717 & 0.4085 & 0.3931 & 0.3937 & 0.3954 \\
\hline
\end{tabular}

Standard errors in parentheses. * Significant at $10 \%,{ }^{* *}$ Significant at $5 \%,{ }^{* * *}$ Significant at $1 \%$.

We expected the lack of significance because RPS Binary is a non-normally distributed dummy and it continues to remain in the sample after the RPS is enacted.

The proportional hazard model uses the probability of RPS adoption as the dependent variable. Straightforward, the hazard model drops the data points after the RPS has been adopted since these values would otherwise bias the estimates. As argued above, it is crucial to exclude state-years after RPS enactment because RPS policies 
may have a reversed effect on the contributions of interest groups, i.e. the independent variable may well be endogenous to the dependent variable if it remains in the sample after having switched from " 0 " to " 1 ".

We perform a Durbin-Wu-Hausman to test for endogeneity, as recommended by Davidson and MacKinnon (1993). The result verifies the hypothesis that REI and CEI contributions are endogenous to both dependent variables. That means REI and CEI contributions are affected by the adoption and stringency of a RPS.

Interestingly, R-Square as a measure of model determination increases by the factor of two when we use the ISI as dependent variable. Yin and Powers's (2009) incremental share indicator is much more normally distributed than the RPS Binary. However, the ISI consists of only 129 data points that are not zero and is still strongly left-tailed. The tobit model excludes these state-years in which no RPS is in place by a lower limit. The tobit model should thus produce more significant results.

\subsection{What Drives the Adoption of a RPS?}

Table 4 presents the results of the proportional hazard model (II). The estimation investigates the drivers of policy adoption which as considered in the first research question. Absolute contributions do not relate significantly to RPS Binary. We argued above that state characteristics such as the size or gubernatorial elections impact absolute values. Thus we should use ratios.

The ratios $R E I-R$ and $C E I-R$ verify our initial theoretical hypothesis: REI-R has a positive impact on the probability of RPS adoption while CEI-R has a negative impact. More specifically, an increase of $R E I-R$ by one standard deviation increases the probability of RPS adoption by $65 \%$. An increase of $C E I-R$ by one standard deviation decreases the odds of RPS adoption by $33 \%$. Both links are highly significant.

Referring to our theoretical assumptions, we argue that policymakers are sensitive to private interest contributions. They know that REI benefit from a RPS while CEI prefer to keep conventional energy capacities online. Thus, policymakers factor the relative contributions of CEI and REI into their decision making process. They are less willing to adopt a RPS if CEI contributions are high. In contrast, they endorse such policy if REI contributions are high. Of course, other aspects also determine the ultimate decision and we will discuss them next. However, the hazard model showed that CEI and REI contributions do make a difference at a statistically significant level.

The $G O V-D$ and $G O V-R$ interaction terms reveal an interesting pattern. First, REI-R has a significant positive (64\%) effect on the odds if there is a democratic governor in office. In other words, REI contributions work if there is a presumably likeminded (see LCV Score discussion above) governor in office. However, if the governor is a Republican, he or she can veto the adoption of a RPS. That may explain why REI-R spending does not have a significant effect on RPS adoption if a Republican is governor. Another reason can be that Democrats receive significant REI contributions (see Figure 5) while the amount that is donated to Republicans is just too small.

Second, CEI-R has a significant negative $(-24 \%)$ effect on RPS adoption if the governor is a Democrat and a significant negative (-100\%) effect on RPS adoption if the governor is a Republican. Therefore, CEI contributions decrease the likelihood of RPS adoption regardless of the party affiliation of the governor. However, the effect of CEI$\mathrm{R}$ is much larger if there is a Republican in office than if a Democrat is governor. In 
other words, CEI contributions de-motivate politician across the spectrum to adopt a RPS. CEI contributions to politicians in states with a Republican governor seem to be especially effective.

The $R E G$ interaction terms show that the level of lobby regulation as quantified by Newmark's (2005) index, does not largely affect the size of the coefficients. A technical reason is that $R E G$ vary across states only. Nevertheless, this model receives the lowest AIC and BIC scores among all models. These scores show that interacting the $R E G$ variable with the CEI and REI contributions increases the overall fit of the model. The REG thus captures otherwise omitted state specific characteristics that are not captured by the state clusters already. A polity reason can be that the number of lobby regulations does not largely decrease the effectiveness of CEI and REI lobbying.

Table 4 - Hazard Model Results - Coefficients and Odd-Ratios

\begin{tabular}{|c|c|c|c|c|c|c|c|c|}
\hline \multirow[b]{3}{*}{ REI-A } & \multicolumn{8}{|c|}{ RPS Binary } \\
\hline & \multicolumn{2}{|c|}{ (H_B_1) } & \multicolumn{2}{|c|}{ (H_B_2) } & \multicolumn{2}{|c|}{ (H_B_3) } & \multicolumn{2}{|c|}{ (H_B_4) } \\
\hline & $\begin{array}{l}0.097 \\
(0.094)\end{array}$ & $10 \%$ & & & & & & \\
\hline CEI-A & $\begin{array}{l}-0.135 \\
(0.222)\end{array}$ & $-13 \%$ & & & & & & \\
\hline REI-R & & & $\begin{array}{l}0.499^{* * *} \\
(0.178)\end{array}$ & $65 \%$ & & & & \\
\hline CEI-R & & & $\begin{array}{l}-0.408^{* * *} \\
(0.151)\end{array}$ & $-33 \%$ & & & & \\
\hline REI-R x GOV-D & & & & & $\begin{array}{l}0.492^{* * * *} \\
(0.162)\end{array}$ & $64 \%$ & & \\
\hline CEI-R x GOV-D & & & & & $\begin{array}{l}-0.281^{* * *} \\
(0.095)\end{array}$ & $-24 \%$ & & \\
\hline REI-R x GOV-R & & & & & $\begin{array}{l}-0.069 \\
(0.149)\end{array}$ & $-7 \%$ & & \\
\hline CEI-R x GOV-R & & & & & $\begin{array}{l}-7.698^{*} \\
(4.451)\end{array}$ & $-100 \%$ & & \\
\hline REI-R x REG & & & & & & & $\begin{array}{l}0.450^{* * *} \\
(0.139)\end{array}$ & $57 \%$ \\
\hline CEI-R x REG & & & & & & & $\begin{array}{l}-0.423^{* * *} \\
(0.136)\end{array}$ & $-34 \%$ \\
\hline GOV-R & $\begin{array}{l}-0.647 \\
(0.449)\end{array}$ & $-48 \%$ & $\begin{array}{l}-0.658 \\
(0.462)\end{array}$ & $-48 \%$ & $\begin{array}{l}-0.210 \\
(0.600)\end{array}$ & $-19 \%$ & $\begin{array}{l}-0.656 \\
(0.457)\end{array}$ & $-48 \%$ \\
\hline PUB-R & $\begin{array}{l}-5.047^{* *} \\
(2.188)\end{array}$ & $-99 \%$ & $\begin{array}{l}-5.115^{* *} \\
(2.065)\end{array}$ & $-99 \%$ & $\begin{array}{l}-4.946^{* *} \\
(2.295)\end{array}$ & $-99 \%$ & $\begin{array}{l}-5.019^{* *} \\
(2.071)\end{array}$ & $-99 \%$ \\
\hline N-RPS & $\begin{array}{l}-0.400 \\
(0.384)\end{array}$ & $-33 \%$ & $\begin{array}{l}-0.416 \\
(0.378)\end{array}$ & $-34 \%$ & $\begin{array}{l}-0.437 \\
(0.385)\end{array}$ & $-35 \%$ & $\begin{array}{l}-0.382 \\
(0.383)\end{array}$ & $-32 \%$ \\
\hline INC & $\begin{array}{l}-0.455 \\
(4.692)\end{array}$ & $-37 \%$ & $\begin{array}{l}-0.129 \\
(4.573)\end{array}$ & $-12 \%$ & $\begin{array}{l}0.001 \\
(4.736)\end{array}$ & $0 \%$ & $\begin{array}{l}0.093 \\
(4.661)\end{array}$ & $10 \%$ \\
\hline E-EMPL & $\begin{array}{l}-0.668 \\
(0.890)\end{array}$ & $-49 \%$ & $\begin{array}{l}-0.701 \\
(0.928)\end{array}$ & $-50 \%$ & $\begin{array}{l}-0.380 \\
(0.806)\end{array}$ & $-32 \%$ & $\begin{array}{l}-0.604 \\
(0.864)\end{array}$ & $-45 \%$ \\
\hline NAA & $\begin{array}{l}0.720^{* * *} \\
(0.263)\end{array}$ & $106 \%$ & $\begin{array}{l}0.748^{* * * *} \\
(0.250)\end{array}$ & $111 \%$ & $\begin{array}{l}0.682^{* * *} \\
(0.253)\end{array}$ & $98 \%$ & $\begin{array}{l}0.758^{* * * *} \\
(0.260)\end{array}$ & $113 \%$ \\
\hline RES-CAP & $\begin{array}{l}-0.131 \\
(0.272\end{array}$ & $-12 \%$ & $\begin{array}{l}-0.144 \\
(0.289)\end{array}$ & $-13 \%$ & $\begin{array}{l}-0.144 \\
(0.270)\end{array}$ & $-13 \%$ & $\begin{array}{l}-0.146 \\
(0.295)\end{array}$ & $-14 \%$ \\
\hline Y1998 & (omit & & (omi & & (omi & & (omi & \\
\hline Y1999 & (omit & ed) & (omi & & (omi & ed) & (omi & \\
\hline Y2000 & $\begin{array}{l}0.035 \\
(0.660)\end{array}$ & $4 \%$ & $\begin{array}{l}0.005 \\
(0.633)\end{array}$ & $0 \%$ & $\begin{array}{l}-0.017 \\
(0.658)\end{array}$ & $-2 \%$ & $\begin{array}{l}-0.031 \\
(0.645)\end{array}$ & $-3 \%$ \\
\hline Y2001 & $\begin{array}{l}0.093 \\
(0.672)\end{array}$ & $10 \%$ & $\begin{array}{l}0.061 \\
(0.643)\end{array}$ & $6 \%$ & $\begin{array}{l}0.033 \\
(0.660)\end{array}$ & $3 \%$ & $\begin{array}{l}0.024 \\
(0.653)\end{array}$ & $2 \%$ \\
\hline Y2002 & $\begin{array}{l}0.086 \\
(0.657)\end{array}$ & $9 \%$ & $\begin{array}{l}0.035 \\
(0.598)\end{array}$ & $4 \%$ & $\begin{array}{l}0.002 \\
(0.603)\end{array}$ & $0 \%$ & $\begin{array}{l}-0.033 \\
(0.597)\end{array}$ & $-3 \%$ \\
\hline Y2003 & $\begin{array}{l}0.220 \\
(0.616)\end{array}$ & $25 \%$ & $\begin{array}{l}0.177 \\
(0.586)\end{array}$ & $19 \%$ & $\begin{array}{l}0.160 \\
(0.610)\end{array}$ & $17 \%$ & $\begin{array}{l}0.139 \\
(0.598)\end{array}$ & $15 \%$ \\
\hline
\end{tabular}




\begin{tabular}{|c|c|c|c|c|c|c|c|c|}
\hline Y2004 & $\begin{array}{l}0.236 \\
(0.603)\end{array}$ & $27 \%$ & $\begin{array}{l}0.199 \\
(0.581)\end{array}$ & $22 \%$ & $\begin{array}{l}0.166 \\
(0.606)\end{array}$ & $18 \%$ & $\begin{array}{l}0.168 \\
(0.591)\end{array}$ & $18 \%$ \\
\hline Y2005 & $\begin{array}{l}0.289 \\
(0.588)\end{array}$ & $33 \%$ & $\begin{array}{l}0.256 \\
(0.563)\end{array}$ & $29 \%$ & $\begin{array}{l}0.224 \\
(0.585)\end{array}$ & $25 \%$ & $\begin{array}{l}0.222 \\
(0.571)\end{array}$ & $25 \%$ \\
\hline Y2006 & $\begin{array}{l}0.367 \\
(0.584)\end{array}$ & $44 \%$ & $\begin{array}{l}0.342 \\
(0.563)\end{array}$ & $41 \%$ & $\begin{array}{l}0.307 \\
(0.584)\end{array}$ & $36 \%$ & $\begin{array}{l}0.307 \\
(0.571)\end{array}$ & $36 \%$ \\
\hline Fixed effects & \multicolumn{2}{|c|}{ Yes } & \multicolumn{2}{|c|}{ Yes } & \multicolumn{2}{|c|}{ Yes } & \multicolumn{2}{|c|}{ Yes } \\
\hline $\mathbf{N}$ & \multicolumn{2}{|c|}{350} & \multicolumn{2}{|c|}{350} & \multicolumn{2}{|c|}{350} & \multicolumn{2}{|c|}{350} \\
\hline Correctly classified & \multicolumn{2}{|c|}{$93.43 \%$} & \multicolumn{2}{|c|}{$93.66 \%$} & \multicolumn{2}{|c|}{$93.37 \%$} & \multicolumn{2}{|c|}{$93.08 \%$} \\
\hline $\begin{array}{l}\text { Pseudo } \\
\text { R-Square }\end{array}$ & \multicolumn{2}{|c|}{0.400} & \multicolumn{2}{|c|}{0.411} & \multicolumn{2}{|c|}{0.420} & \multicolumn{2}{|c|}{0.421} \\
\hline
\end{tabular}

Standard errors in parentheses. * Significant at $10 \%$, ** Significant at $5 \%,{ }^{* * *}$ Significant at $1 \%$.

The models classified more than $93 \%$ of all observations correctly. Pearson's goodnessof-fit chi-squared tests are not statistically significant. We conclude that the model fits well (Cameron and Trivedi 2009). The Pseudo R-Square that we reported at the end of the table is also considerably high. The estimations explain $40 \%$ and more of the information in the data.

The baseline shows that the general probability of RPS adoption has been mostly increasing over time. While the probability increases slightly up to 2002 , there is a sudden increase in 2003. Afterwards, the baseline stabilizes again. Without drifting into speculations, one could argue that 2002 and 2003 were very special years for the U.S. energy landscape. In 2002, the $107^{\text {th }}$ Congress debated the federal "Energy Policy Act of 2002" as a bundle of measures against the steady increase in oil prices. In 2003, it adopted the "Clear Skies Act of 2003". In the same year, the Northeastern blackout left 45 million U.S. Americans without electricity. California had just ended its energy crisis and the Enron scandal began to surface. These and other cross-state effects could have contributed to the jump of the baseline in 2003 .

A final glance at the suite of controls provides two robust results. First, a Republican leaning public opinion decreases the chance of RPS adoption. Thus, policymakers are sensitive to their constituency's ideological stance. Second, states with large non-attainment areas are more likely to implement a RPS. Public health issues seem to drive the energy transition. Lyon and Yin (2010) also found a positive but insignificant link between the $N A A$ Index and RPS adoption. The other control variables do not turn out to be at a statistically significant level.

\subsection{What Drives the Stringency of a RPS?}

The tobit model concentrates on the state-years in which there is a RPS in place. The second research question asked for the determinants of policy stringency, which we quantify by means of the incremental share indicator (Yin and Powers 2009). The regression output in Table 5 shows that absolute contributions do not have a statistically significant impact on the dependent variable. However, as seen before in the hazard model, the relative contributions come at significant levels. We verify the hypothesis that REI contributions have a positive impact on the stringency of RPS schemes while CEI contributions appear to make them weaker. The effect is similar if the governor is a Democrat, while the significances disappear if a Republican is in office. In the fourth specification we interact the CEI and REI ratios with the $R E G$ index that represents the number of lobbying regulations. We find that CEI contributions keep their significant negative impact while REI contributions lose the significance. 
What does that mean? We argue that high REI contributions motivate policymakers to implement a stronger RPS. As a result, more RES-E needs to be produced to meet the RPS requirement. More RES-E generation benefits the constituency of REI interests. Vice versa, more CEI contributions tend to motivate politicians to implement a weaker RPS. As a consequence, more conventional energy can remain in the portfolio. This is a benefit for the CEI. The overall effects seem to be driven by states with a Democratic governor and if there are only few lobby regulations in place. The absence of significant coefficients in the opposing scenarios (Republican governor, high $R E G$ index) does not indicate that these situations are not sensitive to contributions. The signs are still intuitive but the lack of significance does not allow for a solid interpretation.

The suite of controls behaves similar to the hazard model. A Republican leaning public opinion makes RPS policies, once implemented, less stringent. In contrast, public health costs, caused by people living in non-attainment areas, have a positive effect on the stringency of RPS policies. Both links verify our hypothesis while the remaining controls turn out to be insignificant. The baseline is different to the hazard baseline. While the hazard baseline sharply increased in 2003, the tobit baseline that captures the underlying trend in the stringency of RPS policies remains stable. One reason is that the majority of RPS policies have been enacted after 2003, the period that is mostly captured by the tobit model. Another reason can be that politicians react to cross-state impacts mainly by policy-making and less by policy-redesigning.

Table 5 - Tobit Regression Results

\begin{tabular}{|c|c|c|c|c|}
\hline & \multicolumn{4}{|c|}{ ISI } \\
\hline & (T_I_1) & (T_I_2) & (T_I_3) & (T_I_4) \\
\hline \multirow[t]{2}{*}{ REI-A } & 0.155 & & & \\
\hline & 0.147 & & & \\
\hline \multirow[t]{2}{*}{ CEI-A } & -0.064 & & & \\
\hline & 0.193 & & & \\
\hline \multirow[t]{2}{*}{ REI-R } & & $0.228^{*}$ & & \\
\hline & & 0.128 & & \\
\hline \multirow[t]{2}{*}{ CEI-R } & & $-0.016^{* *}$ & & \\
\hline & & 0.008 & & \\
\hline \multirow[t]{2}{*}{ REI-R x GOV-D } & & & $0.189^{*}$ & \\
\hline & & & 0.113 & \\
\hline \multirow{2}{*}{ CEI-R x GOV-D } & & & $-0.011^{*}$ & \\
\hline & & & 0.007 & \\
\hline \multirow[t]{2}{*}{ REI-R x GOV-R } & & & -0.019 & \\
\hline & & & 0.079 & \\
\hline \multirow[t]{2}{*}{ CEI-R x GOV-R } & & & -0.006 & \\
\hline & & & 0.004 & \\
\hline \multirow[t]{2}{*}{ REI-R x REG } & & & & 0.217 \\
\hline & & & & 0.140 \\
\hline \multirow[t]{2}{*}{ CEI-R x REG } & & & & $-0.017^{*}$ \\
\hline & & & & 0.009 \\
\hline \multirow[t]{2}{*}{ GOV-R } & -0.726 & -0.755 & -0.720 & -0.743 \\
\hline & 0.517 & 0.548 & 0.556 & 0.541 \\
\hline \multirow[t]{2}{*}{ PUB-R } & $-1.929^{*}$ & $-1.982^{*}$ & $-1.984^{*}$ & $-1.936^{*}$ \\
\hline & 1.005 & 1.162 & 1.160 & 1.146 \\
\hline \multirow[t]{2}{*}{ N-RPS } & -0.241 & -0.301 & -0.296 & -0.292 \\
\hline & 0.821 & 0.869 & 0.867 & 0.863 \\
\hline \multirow[t]{2}{*}{ INC } & 1.493 & 1.524 & 1.589 & 1.458 \\
\hline & 1.900 & 1.938 & 1.946 & 1.918 \\
\hline \multirow[t]{2}{*}{ E-EMPL } & 0.109 & 0.089 & 0.085 & 0.092 \\
\hline & 0.349 & 0.393 & 0.395 & 0.389 \\
\hline \multirow[t]{2}{*}{ NAA } & $0.584^{*}$ & $0.631^{* *}$ & $0.615^{* *}$ & $0.634^{* *}$ \\
\hline & 0.304 & 0.298 & 0.298 & 0.297 \\
\hline Y1998 & (omitted) & (omitted) & (omitted) & (omitted) \\
\hline
\end{tabular}




\begin{tabular}{lllll} 
Y1999 & 0.068 & 0.066 & 0.060 & 0.065 \\
Y2000 & 0.059 & 0.087 & 0.085 & 0.087 \\
& 0.128 & 0.125 & 0.120 & 0.124 \\
Y2001 & 0.108 & 0.138 & 0.135 & 0.137 \\
& 0.125 & 0.127 & 0.122 & 0.125 \\
Y2002 & 0.124 & 0.154 & 0.151 & 0.153 \\
& 0.140 & 0.149 & 0.147 & 0.147 \\
Y2003 & 0.134 & 0.161 & 0.160 & 0.159 \\
& 0.182 & 0.183 & 0.181 & 0.181 \\
Y2004 & 0.151 & 0.182 & 0.181 & 0.181 \\
& 0.201 & 0.199 & 0.198 & 0.195 \\
Y2005 & 0.148 & 0.180 & 0.179 & 0.177 \\
& 0.191 & 0.194 & 0.191 & 0.193 \\
Y2006 & 0.151 & 0.180 & 0.178 & 0.179 \\
& 0.190 & 0.211 & 0.209 & 0.209 \\
\hline Sigma & 0.154 & 0.184 & 0.183 & 0.183 \\
\hline Fixed Effects & $0.391^{* * *}$ & $0.396^{* * *}$ & $0.396^{* * *}$ & $0.396^{* * *}$ \\
\hline $\mathbf{N}$ & 0.093 & 0.096 & 0.096 & 0.095 \\
\hline Pseudo R-Square & Yes & Yes & Yes & Yes \\
\hline \hline Standard errors in parentheses. * Significant at $10 \%, * *$ Significant at $5 \%,{ }^{* * *}$ Significant at $1 \%$.
\end{tabular}

The sample size is very small. Future studies will certainly make more accurate estimations because they can work with an increasing number of state-years that have a RPS in place. However, our estimates are robust across model specification. The Pseudo R-Square is lower than in the hazard model but still considerably high.

\section{Conclusion}

This article combined theoretical reasoning and empirical analysis. We applied the common agency model developed by Dixit et al. (1997) to the puzzle of renewable energy policy making. Henceforward we elaborated model specifications that explained how the decisions of policymakers (i) to enact a RPS and (ii) to set the stringency of the RPS after enactment are driven by both social welfare considerations and financial contributions from private industrial interests.

We went on to quantify the financial contributions by conventional energy interests (CEI) and renewable energy interests (REI) that were donated to U.S. statelevel policymakers between 1998 and 2010. We found that CEI contribute more to Republicans than to Democrats while REI contributions are mostly given to Democrats.

By means of a proportional hazard model, we revealed statistically significant links between the contributions and the likelihood of a state to adopt a RPS. In short, CEI contributions have a negative impact on the probability of RPS adoption while REI contributions have a positive impact. We conclude that policymakers are sensitive to private interest contributions. REI contributions signal support for a RPS while CEI contributions indicate opposition. We assume that policymakers know that REI benefit from a RPS while CEI prefer its absence. Thus, the hazard model showed that this presumable connection stands up to empirical scrutiny. Public health issues, proxied by the EPA's non-attainment area index, also have a driving effect on the likelihood of RPS adoption. On the other hand, the odds are also affected by public opinion. The impact of our control for a Republican leaning public option turned out to be negative.

By means of a tobit regression model, we revealed similar but less significant links. After a RPS is implemented, REI contributions appear to have a positive impact 
on the stringency of the policy. In contrast, CEI contributions come with a negative impact. The same controls, public health and public opinion, remain robust for all model specifications.

From a theoretical perspective the results verify our key hypothesis. They prove that policymakers set the optimal level of RES-E not only by maximizing benefits over social welfare but they also integrate financial contributions from private industrial interests. From an empirical perspective the results show that policymakers pay back the financial contributions by means of policy choices and - albeit limited - also by policy stringency. Future studies should not rely on binary codes to assess the impact of private interests anymore but should use more nuanced indicators such as our financial contributions. 


\section{References}

Aidt, T. S., 1998. Political internalization of economic externalities and environmental policy. Journal of Public Economics 69(1), 1 - 16.

Cameron, A.C., Trivedi, K.T., 2009. Microeconomics using Stata. Bloomington, Indiana: Stata Press.

Chandler, J., 2009. Trendy solutions. Why do states adopt Sustainable Energy Portfolio Standards? Energy Policy 37(8), 3274 - 3281.

Davidson, R., MacKinnon, J.G., 1993. Estimation and Inference in Econometrics, New York, Oxford University Press.

Database of State Incentives for Renewable Energy (DSIRE), 2012. Database of State Incentives for Renewables and Efficiency. January. Accessed at http:// www.dsireusa.org/.

Delmas, M. A., Montes-Sancho, M. J., 2011. U.S. state policies for renewable energy: Context and effectiveness. Energy Policy 39(5), 2273 - 2288.

Dixit, A., 1996. Special-interest lobbying and endogenous commodity taxation. Eastern Economic Journal 22, 375 - 388.

Dixit, A., Grossman, G.M., Helpman, E., 1997. Common agency and coordination: General theory and application to government policy making. Journal of Political Economy 105(4), 752 - 769.

Finon, D., Menanteau, P., 2004. The static and dynamic efficiency of instruments of promotion of renewables. Energy Studies Review 12(1), 53 - 82.

Fischer, C., Newell, R.G., 2008. Environmental and technology policies for climate mitigation. Journal of Environmental Economics and Management 55(2), 142 - 162.

Groba, F., Indvik, J., Jenner, S., 2011. Assessing the Strength and Effectiveness of Renewable Electricity Feed-in-Tariffs in European Union Countries. Discussion Paper \# 1176, DIW Berlin, Berlin.

Grossman, G.M., Helpman, E., 1994. Protection for sale. American Economic Review $84,833-850$.

Huang, M.-Y., Alavalapati, J.R., Carter, D.R., Langholtz, M.H., 2007. Is the choice of renewable portfolio standards random? Energy Policy 35(11), 5571 - 5575.

Jenkins, P., 1995. Easy Estimation Methods for Discrete-Time Duration Models. Oxford Bulletin of Economics and Statistics 57(1), 129 - 138.

Jenner, S., Chan, G., Frankenberger, R., Gabel, M., 2012. What Drives States to Support Renewable Energy? The Energy Journal 33(2), 1 - 12.

Kiefer, N.M.,1988. Economic duration data and hazard functions. Journal of Economic Literature 26(2), $646-679$.

Knittel, C.R., 2006. The adoption of state electricity regulation. The role of interest groups. Journal of Industrial Economics 54(2), 201 - 222.

League of Conservation Voters, 2011. Environmental Scorecard, 1998-2010 scorecards. October. Accessed at http://www.lcv.org/scorecard/scorecard-archives/. 
Lyon, T.P., Yin, H., 2010. Why do states adopt renewable portfolio standards? An empirical investigation. The Energy Journal 31(3), 133 - 157.

Menanteau, P., Finon, D., Lamy, M., 2003. Prices versus quantities: Choosing policies for promoting the development of renewable energy. Energy Policy 31(8), 799 - 812.

National Institute on Money in State Politics, 2011. State contributions. All state campaign contribution records. November. Accessed at http://data.influenceexplorer.com/bulk/.

Nese, G., 2002. Green certificates in an international market. Institute for Research in Economics and Business Administration (SNF) University of Bergen, SNF Working paper 75/02, Bergen.

Newmark, A.J., 2005. Measuring State Legislative Lobbying Regulation, 1990-2003. State Politics \& Policy Quarterly 5(2), 182 - 191.

Persson, T., Tabellini, G., 2000. Political Economics: Explaining Economic Policy. Cambridge and London: MIT Press.

Schmalensee, R., 2011. Evaluating Policies to Increase the Generation of Electricity from Renewable Energy. M.I.T. Center for Energy and Environmental Policy Research Working Paper 2011-008, Cambridge, M.A.

U.S. Bureau of Labor Statistics, 2011. Databases. Employment. October. Accessed at http://www.bls.gov/data/\#employment.

U.S. Bureau of Economic Analysis, 2011. Regional Economic Accounts. State Annual Personal Income \& Employment. December. Acessed at http://www.bea.gov/regional/index.htm.

U.S. Energy Information Administration, 2011. The Electric Power Annual Database. U.S. Energy Information Administration, Washington, D.C.

U.S. Environmental Protection Agency, 2011. The Green Book Nonattainment Areas for Criteria Pollutants. December. Accessed at http://www.epa.gov/oar/oaqps/greenbk/.

U.S. National Conference of State Legislatures, 2011. Legislator Data (private).

Weitzman, M.L., 1974. Prices vs. quantities. The Review of Economic Studies 41(4), 477 - 491.

Yin, H., Powers, N., 2010. Do state renewable portfolio standards promote in-state renewable generation? Energy Policy 38(2), 1140 - 1149. 


\section{Appendix}

The FOC of the benchmark case (no lobbying) implicitly defines the optimal level $\alpha^{*}$ :

$$
\frac{\partial S W}{\partial \alpha}=0=\pi_{\alpha}{ }^{R}-N H_{\alpha}(E)-N P x_{\alpha}(P)+\pi_{\alpha}{ }^{F}+\pi_{\alpha}{ }^{D}+N\left[u\left(x_{\alpha}(P)\right)\right]
$$

The first three terms are positive: the profits for the renewables producers increase, pollution decreases and utility of consuming the numéraire increases with an increase in $\alpha$. The other terms in the expression are negative. The profits in the fossil fuel and distribution sector decrease as well as the demand for electricity, so that utility of consuming electricity is lower, when the RPS obligation strengthens. The optimal level of renewables under the RPS, $\alpha^{*}$, is defined by equating these marginal benefits and marginal costs. The objective function of the policymaker that includes campaign contributions from the renewables interest group has the following FOC:

$$
\begin{aligned}
\frac{\partial S W}{\partial \alpha}=0= & \lambda\left[\pi_{\alpha}{ }^{R}-N H_{\alpha}(E)-N P D_{\alpha}(P)+\pi_{\alpha}{ }^{F}+\pi_{\alpha}{ }^{D}+N\left[u\left(D_{\alpha}(P)\right)\right]\right] \\
& +(1-\lambda)\left[\sum_{h \in R E I} \sigma_{h, R} \pi_{\alpha}{ }^{R}-s_{R} N H_{\alpha}(E)\right]
\end{aligned}
$$

This condition implicitly defines the optimal level of the portfolio standard in presence of influence from the renewables interests. Marginal benefits of increasing the level of the standard are larger compared to the benchmark case, which allows us to conclude that the optimal level of the standard is larger than $\alpha^{*}$, we have $\alpha^{R}>\alpha^{*}$. The FOC for the objective function where the policymaker includes campaign contribution from the conventional interests is as follows:

$$
\begin{aligned}
\frac{\partial S W}{\partial \alpha}=0= & \lambda\left[\pi_{\alpha}{ }^{R}-N H_{\alpha}(E)-N P D_{\alpha}(P)+\pi_{\alpha}{ }^{F}+\pi_{\alpha}{ }^{D}+N\left[u\left(D_{\alpha}(P)\right)\right]\right] \\
& +(1-\lambda)\left[\sum_{h \in C E I} \sigma_{h, F} \pi_{\alpha}{ }^{F}\right]
\end{aligned}
$$

This expression implicitly defines $\alpha^{F}$, the optimal standard in presence of the conventional interest group. As the marginal costs of increasing the standard exceed the marginal benefits, the policymaker maximizes his objective function by imposing a level that is lower than in the benchmark, so we have $\alpha^{F}<\alpha^{*}$. 